Working Paper 06-06

Economic History and Institutions Series 01

February 2006
Economic History and Institutions Dept.

Universidad Carlos III de Madrid

Calle Madrid 126

28903 Getafe (Spain)

Fax (34) 916249574

\title{
WAS MALTHUS RIGHT? \\ A VAR ANALYSIS OF ECONOMIC AND DEMOGRAPHIC INTERACTIONS IN PRE-INDUSTRIAL ENGLAND
}

\author{
Esteban A. Nicolini ${ }^{+}$
}

\begin{abstract}
This paper shows that the interaction between economic and demographic variables in England before the onset of modern economic growth did not fit some crucial assumptions of the Malthusian model. I estimated a vector autoregression for data on fertility, nuptiality, mortality and real wages over the period 1541-1840 applying a well-known identification strategy broadly used in macroeconomics. The results show that endogenous adjustment of population to real wages functioned as Malthus assumed only until the 17th century: positive checks disappeared during the 17 th century and preventive checks disappeared before 1740. This implies that the endogenous adjustment of population levels to changes in real wages -one of the cornerstones of the Malthusian model- did not work during an important part of the period usually considered within the "Malthusian regime".
\end{abstract}

Key Words: Malthusian model, VAR, Demography, England

JEL classification numbers: J10, N33.

\footnotetext{
+ I would like to thank Jordi Gali and Albrecht Ritschl for their encouragement and advice and two referees, Nick Crafts, Juan Dolado, Knick Harley, Robert Milward, Jim Oeppen, and Hans-Joachim Voth for their suggestions. This paper has also benefited from comments received at Universidad Torcuato Di Tella, University of Copenhagen, Humboldt University and the European Historical Economic Society Meeting at Lisbon and the European Economic Association meeting in Madrid. Any remaining errors or omissions are my responsibility. Research support was provided by the Spanish Ministry of Science and Technology grant SEC - 2002-01596.

+ Esteban A. Ncolini. Economic History and Institutions Department, University Carlos III Madrid, e-mail: esteban.nicolini@uc3m.es
} 


\section{Introduction}

In recent years, a growing interest in economic growth in the very long run has led to a wide range of theoretical models which try to explain pre-industrial stagnation and modern economic growth in a unified framework. ${ }^{1}$ In general, the former period has been called "Malthusian" because it was argued that the observed stability of income per capita and the slow growth of population correspond closely with some of the predictions of the Malthusian model. The dynamics of the Malthusian model are driven by two key elements. On the one hand, the declining marginal productivity of labor implies that the level of income per capita is a decreasing function of the level of population (which is a proxy for labor input). On the other hand, both fertility and mortality are functions of income per capita: fertility increases with income while mortality decreases. When income per capita is below certain level (its long-run equilibrium), fertility decreases and mortality increases; the result is a decline in the population level and an increase in income per capita. Consequently, for a given technology there is an equilibrium in which fertility and mortality are equal, and population and real wages are constant. Any technological improvement can produce a temporary rise in living standards but, with time, the increase in fertility and the decline in mortality will cause the population to increase pushing down income per capita. Usually, the rapid and sustained growth in income per capita which began in Europe in the nineteenth century is considered to be the end of the Malthusian regime.

However, the empirical implications of the Malthusian model are more complex than simply a tendency of real wage to revert to its long-run equilibrium level together with very slow population growth. For instance, an exogenous increase in the real wage, although temporary, should be followed by an increase in fertility (the preventive check) and a decrease in mortality (the positive check). Moreover, given that Malthus assumed that most of the voluntary control of fertility was achieved by controlling age of marriage and celibacy, the increase in fertility should be associated with an increase in nuptiality.

Testing whether these hypotheses fit the observed patterns in pre-industrial populations is important for several reasons. Firstly, it is still not clear whether the Malthusian model is a good tool to understand European eco-

\footnotetext{
${ }^{1}$ Lucas (2002), Kremer (1993), Galor and Weil (2000), Hansen and Prescott (1998), Kögel and Prskawetz (2001) among others.
} 
nomic and demographic events before the 19th century: while some empirical approaches claim that this could be the case (Lee 1981, Eckstein et al. 1986, Bayley and Chambers 1993, Galloway 1988) others suggest that important qualifications should be taken into consideration (Tsoulouhas 1992, Grantham 1999, Allen 2001, Lee and Anderson 2002, Nicolini 2004). Secondly, some approaches assume that some interactions between demographic and economic variables had a unique pattern before the middle of the 19th century (Lee and Anderson 2002, Bayley and Chambers 1993) while others have shown that significant changes in the demographic pattern were taking place during the 17th and 18th century (Lee 1981, Galloway 1988). A new methodology applied to the best data set of a pre-industrial population can shed some light on these two issues. Thirdly, although there is some consensus in the theoretical literature in christening the pre-industrial period as "Malthusian", most of the models make a, to some extent, arbitrary selection of which elements of the Malthusian model are considered relevant for the analysis. For instance some models assume that mortality is exogenous and fertility endogenous (Galor and Weil 2000, Kögel and Prskawertz 2001) while other models predict that birth rates are constant and all the population adjustment comes from changes in mortality (Lagerlof 2003). The identification of the magnitude and significance of the responses of the variables to the exogenous shocks can help to highlight what is the proper set of "stylized facts" to be explained.

The English series of fertility, mortality, nuptiality and real wages covering the period 1541-1841 is probably the best data set for testing the Malthusian hypotheses. However empirical analysis of the interaction of these variables is difficult because they are all intrinsically endogenous: the three demographic variables depend on real wages and the real wage is a function of the population level which in turn depends on the levels of fertility and mortality. A usual strategy to study their interactions is to design a structural model, in general including specific equations for fertility, mortality, real wages and population growth and to estimate the parameters of these equations. Several models of this kind have been proposed and, although in essence they are very similar, each model tends to include different sets of variables, presents its own version of the structural equations and is estimated with different econometric techniques (Lee 1985b, 1993, Tsoulouhas 1992, Bailey and Chambers 1993). There is another approach in which, instead of defining a priori an underlying structural model, researchers simply represent each variable as a function of the actual and lagged values of the other variables but, of course, 
at the cost of imposing other kinds of restrictions to identify the relevant interactions. The simplest restriction is simply to assume that a subset of the variables was exogenous and to apply standard regressions or estimate distributed-lags models (Lee 1981, Weir 1984, Galloway 1988, Palloni et al. 1996).

In both approaches (with structural models or with distributed-lags models) the problem of identification has, in general, not been fully solved. ${ }^{2}$ Eckstein et al. (1986) introduced the methodology based on vector autoregressions (VAR) into historical-demographic research. This approach allows for estimations with less restrictive specifications and, more importantly, introduces the possibility of distinguishing between the endogenous and the exogenous component of the interaction between variables. This feature is crucial in the context of the Malthusian hypotheses and its importance can be clarified with the following example: on the one hand, when mortality increases, real wages should increase because higher mortality leads to a smaller population which induces higher wages; on the other hand, when real wages increase, mortality should decline (the positive check). One effect predicts a positive relationship between mortality and real wages while the other predicts a negative relationship. If a simple regression between the two variables is fitted, both effects would be mixed and the results would probably be misleading. After the seminal work by Eckstein et al., Hagnell (1991) and Bengtsson and Broström (1997) estimated VAR systems using Swedish data and Lee (1993) discussed the relative advantages of VAR and distributed lags models. ${ }^{3}$

In this paper I estimate a vector autoregression (VAR) system including series of fertility, mortality, nuptiality and real wages for the English economy between 1541-1841. The contributions of the paper are twofold. Firstly, from a methodological point of view in the context of VAR, the paper highlights that annual series of demographic variables can fit very well the identification strategy based on the assumption that some variables can not react contemporaneously to exogenous shocks in other variables. When estimating a VAR with annually based demographic data, the assumption

\footnotetext{
${ }^{2}$ See Lee (1997, p. 1069) for a discussion of the methodological issue and Lee and Anderson (2002) for a new approach using a Kalman filter.

${ }^{3}$ Mills (1994) in an unpublished Ph.D dissertation analyzed the demographic transition in England estimating a VAR system with demographic and economic data but she has focused on the autoregressive representation of the system without recovering the responses of the variables to exogenous shocks.
} 
of contemporaneous stickiness emerges quite easily for at least one variable because birth rates present a natural lag of at least nine months ${ }^{4}$ before reacting to any shock in the other variables and therefore exogenous shocks of birth rates tend to be contemporaneously uncorrelated with other sources of variability in the system.

More importantly, the second contribution of this paper is to show that the English pre-industrial demographic pattern ceased to fit several crucial assumptions of the Malthusian model well before the onset of modern economic growth in the 19th century. For instance, the results of the estimations presented here show that positive checks vanished before the middle of the 17th century while the preventive check disappeared before the middle of the 18th century and was replaced by a negative relationship between real wages and fertility (characteristic of modern demographic patterns). The results also suggest that since the 16th century the preventive check was associated not only with an indirect control of fertility through marriage choices but also with the use of contraceptive practices within marriage.

The structure of the rest of the paper is as follows. In section 2 the data is presented and the statistical properties of the series are analyzed. Section 3 introduces a discussion of the suitability of vector autoregressions in the analysis of demographic data and discusses the identification strategies used in the estimation. In section 4 the results of the estimations are presented and section 5 advances the conclusions. An appendix in section 6 gathers a comprehensive list of graphs and tables which complement the results of section 4 .

\section{The data}

In this paper I use the longest available annual series of crude birth rates, crude death rates, and crude marriage rates ever collected $(C B R, C D R$, and $C M R$ respectively). They track the evolution of the population of England from 1541 to 1870 and were reconstructed by the Cambridge Group for Population and Social Structure (Wrigley and Schofield 1981, Wrigley et al. 1997). Although the methodology and some of the interpretations of the Cambridge Group have motivated some debate, ${ }^{5}$ their results are generally regarded as

\footnotetext{
${ }^{4}$ The lag is usually longer than a year if pregnancy delay is taken into consideration.

${ }^{5}$ See for instance Lee (1985a, 1993) Goldstone (1986), and Lindert (1983).
} 
the best set of demographic data of a pre-industrial population. The three series are depicted in Graph $1^{6}$

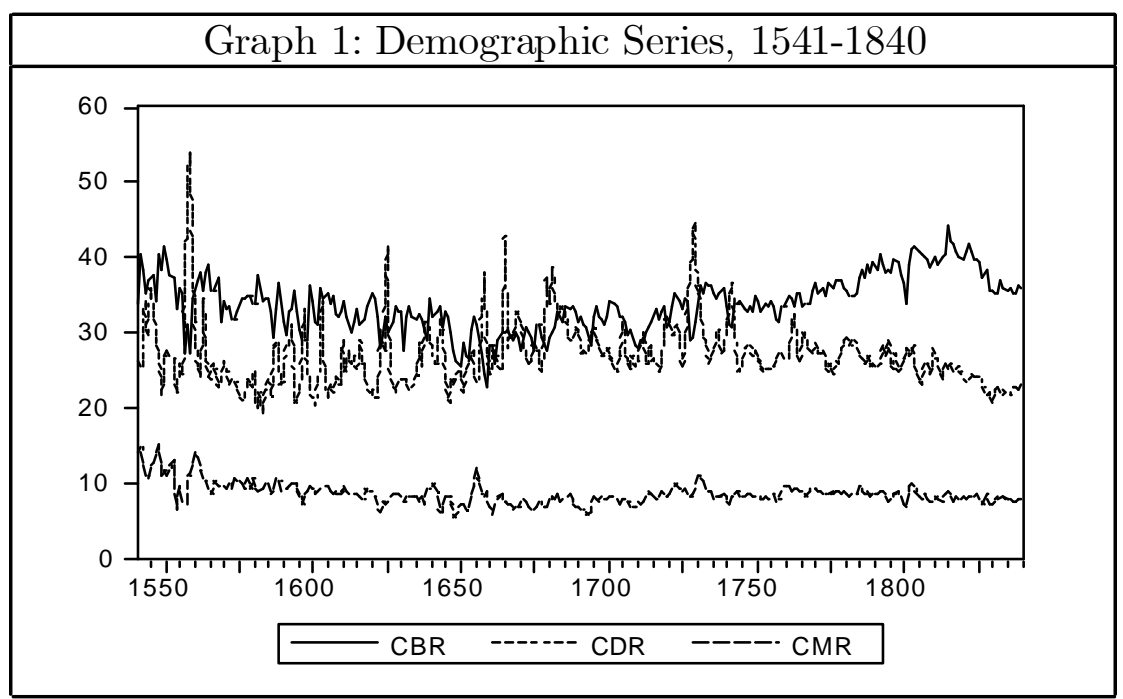

Until very recently, most of the historical research into the evolution of England's pre-industrial economy has relied upon the series of real wages calculated by Phelps-Brown and Hopkins (1956). It represents the real wage of craftsmen and building workers in Oxford between 1260 and 1954. Although this series has been extensively used, it has also been widely criticized in particular because it exaggerates the rigidity of nominal wages and has a considerable number of missing observations requiring interpolation to undertake most of the statistical analysis. Of course, both shortcomings are particularly relevant when short-term interactions are under scrutiny. In this paper I use the series of real wages of laborers in London reconstructed by Allen (2001) (Graph 2). Although the correlation between both series is very high, the new one is much more appealing because it incorporates a more flexible indicator of nominal wages, improves the price index used to deflate the nominal wages and produces a series without missing observations for the whole period under analysis. Regarding the estimation of this paper, both series produce very similar results

\footnotetext{
${ }^{6}$ Although the Cambridge Group have also produced a complete series of population levels for the period under analysis, it is not included in my estimation because, given that migration in this period was very low, most of the variability of population is accounted for by variability of birth and death rates. Including population levels would increase the number of variables without adding independent variability to the system and, hence, making identification more difficult.
} 


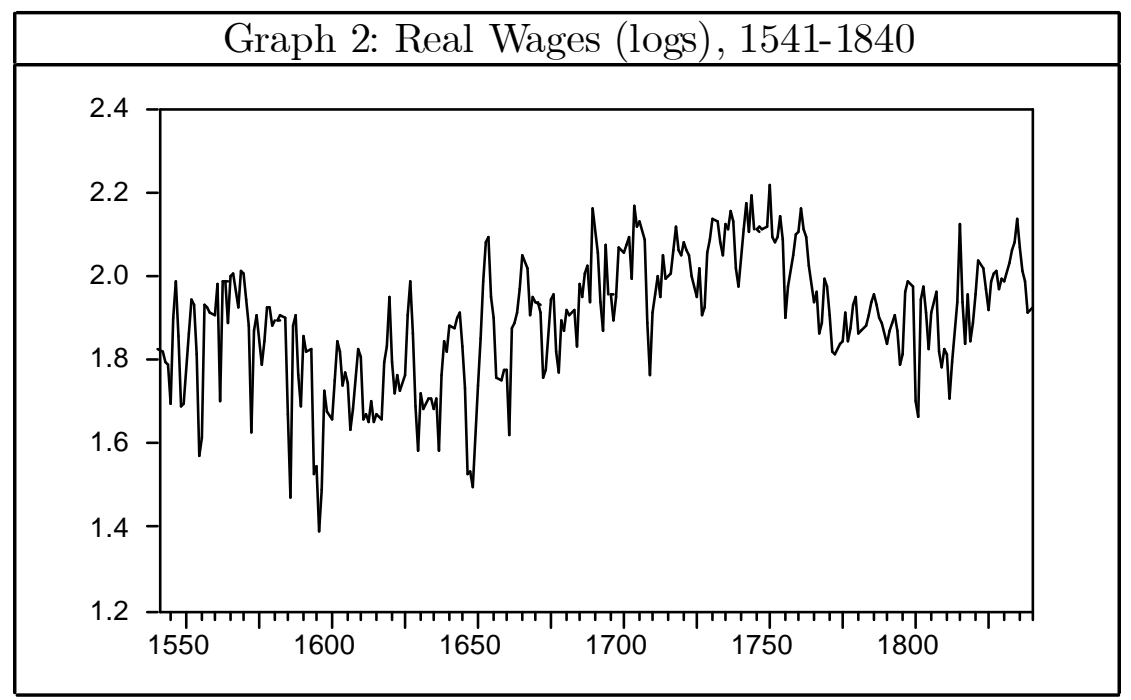

Although data availability makes it possible to extend the analysis until 1870, the sample is restricted to the period 1541-1840 because I want to focus on the period before the onset of the sustained growth in real wages which is usually considered to mark the end of the so-called "Malthusian regime" (Galor 2004). Until 1840 real wages follow a pattern of oscillations around a constant value but in 1870 the change of trend is already noticeable (Allen 2001).

To explore whether the demographic interactions follow a stable pattern during the 300 years before the Industrial Revolution, I present estimations not only for the whole sample (1541-1840) but also for three different periods of 100 years $(1541-1640 ; 1641-1740 ; 1741-1840)$. The first criteria used to define the endpoint for each period was rather pragmatic: each sub-sample would have similar length and would be easily comparable with the results of the seminal work by Lee (1981). In addition, I have applied a loglikelihood ratio (LR) test for structural change for each possible split of the sample between 1561 and 1820. The results (available upon request) show that the estimations are quite unstable in the first 70 years of the sample (until approximately 1610) and then tend to stabilize. After 1611, the local maximums for LR statistic are precisely 1642 and 1743; hence, I decided to keep the original periodization with sub-samples of 100 years which is more intuitive and fits the results of the test quite closely.

The long run properties of the time series involved are crucial not only to specify the econometric model correctly but also to validate some of the assumptions of the Malthusian framework and to corroborate some of its 
predictions. However, until now, surprisingly little has been said about the degree of integration of the series. ${ }^{7}$ The results of the Augmented Dickey Fuller and Phillips-Perron tests for the series of vital rates, and the log of real wages $(L R W)$ are presented in Table 1.

\begin{tabular}{|c|c|c|c|c|}
\hline \multicolumn{5}{|c|}{ TABLE 1: Phillips-Perron and ADF tests } \\
\hline \multicolumn{5}{|c|}{$\begin{array}{c}\text { Phillips-Perron }^{8} \\
\end{array}$} \\
\hline & $C B R$ & $C D R$ & $C M R$ & $L R W$ \\
\hline $\mathrm{PP}$ & -4.51 & -8.29 & -6.52 & -5.71 \\
\hline \multicolumn{5}{|c|}{ ADF Tests $^{9}$} \\
\hline & $C B R$ & $C D R$ & $C M R$ & $L R W$ \\
\hline$q$ & 2 & 3 & 8 & 3 \\
\hline$A D F$ & -3.48 & -5.50 & -3.90 & -4.65 \\
\hline
\end{tabular}

Both tests reject the null of a unit root in the five series at the $5 \%$ significance level which suggests that the vector $Y=\left[C B R_{t}, C D R_{t}, W_{t}, C M R_{t}\right]$ can be assumed to be a covariance stationary in which the variables are affected by shocks with only temporary effects. ${ }^{10}$ This is consistent with the implications of the Malthusian model that birth rates, death rates and real

\footnotetext{
${ }^{7}$ It is well known that the discrimination between a stationary and a $I(1)$ series is very difficult and that the conclusions of the available tests are not necessarily coincident. While Bayley and Chambers (1993) claimed that the series are integrated using non-standard tests, Mills (1994, Ch. 4) reports the ADF tests for the series for the period 1541-1870 and finds that the null hypothesis of a unit root is rejected for CBR, CDR, CMR and real wages.

${ }^{8}$ The estimated regression is $y_{t}=\alpha+\rho y_{t-1}+\varepsilon_{t}$. Lag truncation for Bartlett kernel: 5 . The critical values are: $1 \%:-3.4540 ; 5 \%:-2.8714 ; 10 \%:-2.5720$.

${ }^{9}$ The estimated regression is $\Delta y_{t}=\zeta \Delta y_{t-1}+\ldots+\zeta \Delta y_{t-q+1}+\alpha+\rho y_{t-1}+\varepsilon_{t}$. . The true process has the same specification with $\alpha=0$ and $\rho=0$. The critical values are: $1 \%$ : $-3.4540 ; 5 \%$ : $-2.8714 ; 10 \%$ : -2.5720 . For each variable, an optimal $q$ was chosen following Schwartz's selection criterion.

${ }^{10}$ The presence of unit roots has also been tested (Phillips-Perron test) for each of the three sub-samples in which the data set has been divided. The null of a unit root has been rejected at $5 \%$ in all cases with the exception of CBR in the period 1741-1840. Probably the unusually steady growth of fertility in that period (until 1815) explains a pattern of persistence that makes it difficult to reject the null of a unit root in CBR. If the third sub-sample is extended to 1701-1840, the hypothesis of a unit root is also rejected for the series of CBR. The results of the estimation with this extended sub-sample are very similar to those obtained with the sub-sample 1741-1840.
} 
wages oscillate around their long-run equilibrium level and that demographic and technological shocks produce only temporary deviations. This characterization suggests the study of these short-run out-of-equilibrium dynamics estimating a VAR for the levels of the four variables.

\section{Vector Autoregression with Demographic Variables}

A possible way of scrutinizing the dynamic interaction between a set of $n$ variables is to model the behavior of this set as a Vector Autoregression with a specification of the form

$$
A_{0} Y_{t}=\sum_{j=1}^{s} A_{j} Y_{t-j}+u_{t}
$$

where $Y_{t}$ is a $(n \times 1)$ vector of variables, $u_{t}$ is a $(n \times 1)$ vector containing the shocks in each of the variables, $A_{j}$ is a $(n \times n)$ matrix and

$$
E\left(u_{t} u_{\tau}^{\prime}\right)=\left\{\begin{array}{rr}
I & \text { if } t=\tau \\
0 & \text { otherwise }
\end{array}\right.
$$

In this case each element of $Y_{t}$ depends on its own lagged values and on contemporaneous and lagged values of all the other variables. The shocks $u_{t}$ are sometimes called "fundamental" in the sense that they can be easily linked to a particular variable and that they are "clean" of the contemporaneous effects of the other variables which are already being taken into account with the coefficients of the matrix $A_{0}$.

If $Y_{t}$ is stationary, we can express each variable of the system as a sum of these "fundamental" shocks

$$
A^{*}(L) Y_{t}=u_{t}
$$

(where $L$ is the lag operator and $A^{*}(L)=A_{0}-\sum_{j=1}^{s} A_{j} L^{j}$ ) or

$$
Y_{t}=A^{*}(L)^{-1} u_{t}
$$

Given that the system in (1) is not identified (it is impossible to distinguish between the different equations of the system) it is usually presented in an alternative way 


$$
Y_{t}=\sum_{j=1}^{s} \Phi_{j} Y_{t-j}+\varepsilon_{t}
$$

where

$A_{0}^{-1} u_{t}=\varepsilon_{t}$

$A_{0}^{-1} A_{j}=\Phi_{j}$

and $E\left(\varepsilon_{t} \varepsilon_{t}^{\prime}\right)=\left\{\begin{array}{r}\text { if } t=\tau \\ 0 \quad \text { otherwise }\end{array}\right.$

Although consistent estimations of and the $\Phi_{j}$ 's are easy to obtain by running OLS regressions equation by equation, the estimation of $A_{0}$ is also required to recover the response of the variables to "fundamental" shocks. One of the most usual ways of reducing the free parameters in the system is based on a standard result in time series analysis: lower triangularity of the matrix $A_{0}^{-1}$ is a sufficient condition to identify the system and to recover all the relevant parameters in (1). The lower triangularity of $A_{0}^{-1}$ means that, given a particular ordering inside the vector $Y_{t}$, each variable is allowed to react within the current period to a fundamental shock in any of the variables that precede it, but it must be completely unresponsive to shocks in variables that are lower in the ordering. In a bi-variate example with $Y_{t}=\left[\begin{array}{ll}y_{1 t} & y_{2 t}\end{array}\right]$, recursiveness means that $y_{2 t}$ can freely react to contemporaneous and lagged shocks to $y_{1 t}$ but $y_{1 t}$ can only react to lagged shocks in $y_{2 t}$. This assumption, which is intensively applied in several fields of empirical economics (mainly in macroeconomics and particularly in monetary theory), involves a risky choice of the variables considered "fixed" in the short run. Idiosyncratic inertias and informational flows were used to justify particular orderings (see e.g. Canova 1995a, 1995b; Christiano, Eichenbaum and Evans 1998).

My claim is that annual demographic records match the short-run restriction of VAR closely because an important share of the aforementioned recursiveness arises in a very natural way: any endogenous response of fertility is delayed by nine months of pregnancy plus the lag between the decision to have a child and the moment when conception takes place. Waiting time for conception, which starts at the first ovulation following birth and ends with a conception ranges from a low of about 5 months to high values that can exceed 10 months with an average of 7.5 (Bongaarts 1978).

Consequently, birth rate is a very good candidate to be the first variable 
in the vector Y. ${ }^{11}$ Regarding the other variables I made the assumption that marriage rate influences neither the mortality rate nor real wages within the same year and, consequently, I located CMR as the last variable in the vector $^{12}$. Finally, given that there was no obvious constraint relating CDR and wages, I tentatively placed them as $2 \mathrm{nd}$ and $3 \mathrm{rd}$ variables and estimated the following system

$$
Y_{t}=\left[\begin{array}{llll}
C B R_{t} & C D R_{t} & W_{t} & C M R_{t}
\end{array}\right]
$$

Then, to test the robustness of the results, I estimated the system with alternative orderings in the last three variables and only minor changes in the very short-run dynamics emerged, all the qualitative results presented in next section remaining almost identical. ${ }^{13}$

\section{Results}

The most common way of presenting the results of a VAR estimation is the impulse responses (IR) which show the response over time of each variable in $Y_{t}$ to a shock in each element of $u_{t}$. The shock of each variable is set as one standard deviation of that variable and the evolution of the response is traced through ten periods; period 0 corresponds to the year of the shock. Confidence bands obtained with Montecarlo simulations are included in the graphs with dotted lines. Sometimes it is also useful to consider the sum of the elements of the IR across a certain number of periods which is called accumulated impulse response (AIR). One way to take into account the relative influence of each variable on the variability of the others is to look at the

\footnotetext{
${ }^{11}$ A large incidence of foetal loss can eventually introduce complications into this identification assumption. This potential shortcoming will be considered in further detail in section 4.5 .

${ }^{12}$ Although this argument is less motivated than the assumption regarding birth rates, it is quite in line with the hypotheses about demographic and economic interaction discussed in the literature (Lee 1981, Galloway 1988).

${ }^{13}$ The estimation of 2 implies a choice about the lag length $s$. The four most important criteria to choose optimally $s$ are AIC, BIC, HQ and FPE. The implementation of these criteria indicated 10,2, 3 and 2 lags respectively. It is known that AIC converges to a higher $s$ than the true one as long as the sample increases (see for instance Chatfield, 1996, ch.13) and therefore it is more reasonable to adopt the smaller values. I preferred to use four lags in the estimation as a compromise between the suggestion of AIC and the other criteria but any value of $s$ between 2 and 7 does not produce relevant changes in the results.
} 
variance decomposition ( $\mathrm{VC}$ ) which indicates the portion of total variance of each element of $Y_{t}$ due to each disturbance $u_{t}$. All the results are presented as an appendix in section 6 but I will also include within the body of the text some Graphs with selected IRs to highlight some particularly relevant results.

I will explore four important hypotheses related with the Malthusian model: the existence of positive checks, the existence of preventive checks, the impact of population changes on real wages, and the degree to which the preventive check operated through the regulation of marriages or through the fertility control within marriage. The hypotheses are sequentially taken into consideration sequentially and the discussion focuses not only on the results with the whole sample but also -and more importantly -in each of the three sub-samples (1541-1640, 1641-1740 and 1741-1840) to check whether the demographic interactions change as the English economy approaches the first stages of modern economic growth.

\subsection{The early disappearance of the positive check}

The positive check was identified with misery by Malthus: when population increased at a higher rate than food production, the check operates because income per capita shrinks inducing less and worse food intake, worse health and a higher rate of mortality; hence, the positive check predicts that mortality should decline after an increase in real wages. Past research suggests that positive checks were quite important in pre-industrial Europe but that its magnitude diminished with economic development (Galloway 1988). In England, estimations with distributed-lags models also suggest that the positive check would have been stronger than the preventive check during the 16th and 17th century but it would have weakened with time (Lee 1981). However, some approaches still estimate the positive check assuming parameter stability across the whole period (Lee and Anderson 2002); under this assumption, the estimation suggests that the positive check tends to be weaker than the preventive check.

The four IR in graph 4 depict, for the whole sample and the three subsamples, the response of CDR after a positive shock in wages. The IR obtained using the whole sample (upper-left graph) is consistent with the existence of a positive check: CDR declines for three years (periods 2, 3 and 4 of the graph) and then returns to its average. However, the IR is significantly negative only in the third and fourth year after the shock and the accumulated 
response after ten years is only -1.25 (meaning a reduction of mortality in $4,6 \%$ ) suggesting that positive checks were not really strong.

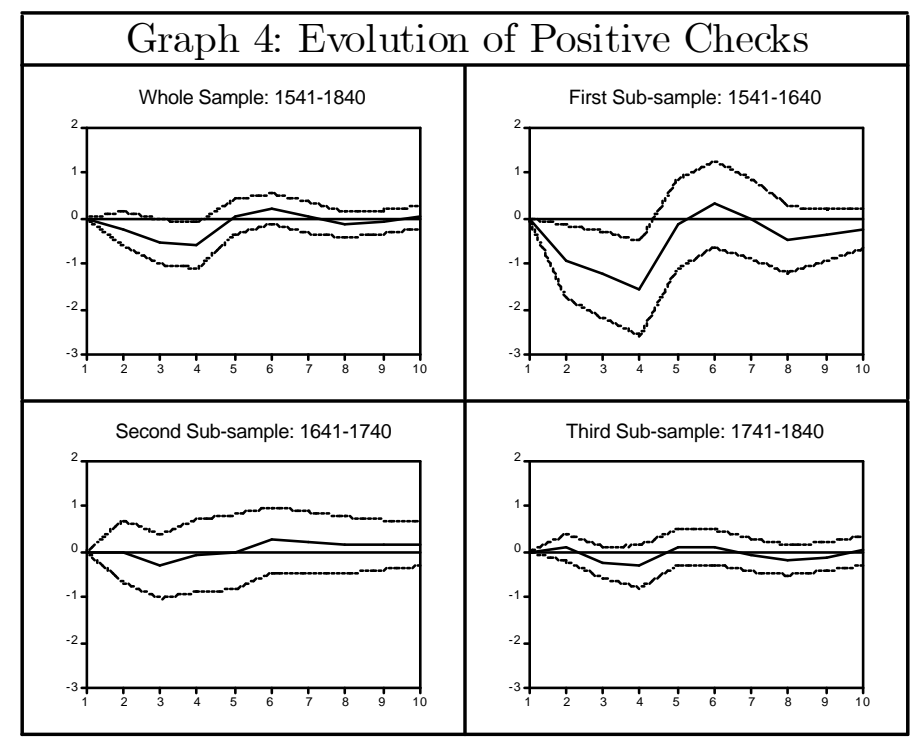

The evolution of the IRs across sub-samples reveals a clear change in the pattern of the positive check across time. The IR of the first subsample is strongly and significantly negative for four years after the shock while it is neither significant nor so strong in the other two sub-samples. In the first sub-sample, the accumulated reduction of mortality over ten years is more than $17 \%$ of average mortality ${ }^{14}$ while in the other two sub-samples the effect is considerably smaller (an increase of $2 \%$ and a decrease of $2 \%$ respectively). The share of the CDR's variance explained by wages is $17.7 \%$ in the first sub-sample (Table 7) and less than $5 \%$ in the other two sub-samples (Tables 8 and 9 with $1.72 \%$ and $4.82 \%$ respectively).

Summarizing, until 1640 the positive check is strong and statistically significant and it explains an important part of the variability of mortality. Afterwards, this check disappears and the elasticity of mortality with respect to real wages is basically zero. The first implication of these results is that one of the key elements to restore the equilibrium in the Malthusian model vanished during the 17th century. The second implication is that assuming a stable positive check during pre-industrial times could be misleading.

\footnotetext{
${ }^{14}$ This number $(17 \%)$ comes from the accumulated response of CDR to a shock in real wages in the first sub-sample (-4.604 in Table 3) as a percentage of the average level of $\mathrm{CDR}$ in the same sub-sample. The other percentages are calculated in a similar way.
} 


\subsection{The early disappearance of the preventive check}

The other equilibrating mechanism in the Malthusian model -the preventive check- is based on the positive relationship between fertility and real wages. In a population with operative preventive checks, birth rates should rise after an increase in income per capita and, in a VAR system, this should translate into a positive value of the impulse response of birth rates after a shock in wages.

Available evidence for pre-industrial Europe in general suggests that the preventive check was quite strong, stable, and insensitive to changes in level of development (Galloway 1988). The estimation by Lee (1981) suggests that in England the preventive check would have been strikingly homogeneous across sub-periods and, during the 18th century, more significant than positive checks which faded out well before the Industrial Revolution (Lee 1981). This finding is rather puzzling given that it has been shown that during the 18th century most of the upsurge of population growth can be explained by the increase in fertility (Wrigley and Schofield 1981, Wrigley et al. 1997) while real wages were stagnant or even declining (Allen 2001). If preventive checks were so strong and wages did not increase at all... why did fertility increase?

My estimation of the evolution of the preventive checks can be traced by looking at the IR tracking the response of CBR after a shock in real wages for the whole sample and the three sub-samples (Graph 5). They show that the preventive check was very noticeable and statistically significant until 1740 but it changed dramatically in the period 1740-1840. The IR of the first two sub-samples are quite similar (with higher persistence in the second sub-sample) and they show an obvious increase in fertility following an improvement in real wages. However this pattern changes dramatically in the third sub-sample which presents a small and non-significant positive response during one year and a negative and statistically significant response from year 4 to year $10 .{ }^{15}$

\footnotetext{
${ }^{15}$ The response of CBR to a shock in wages is more persistent in the third sub-sample. See the discussion on the statistical properties of the series in section 2 .
} 


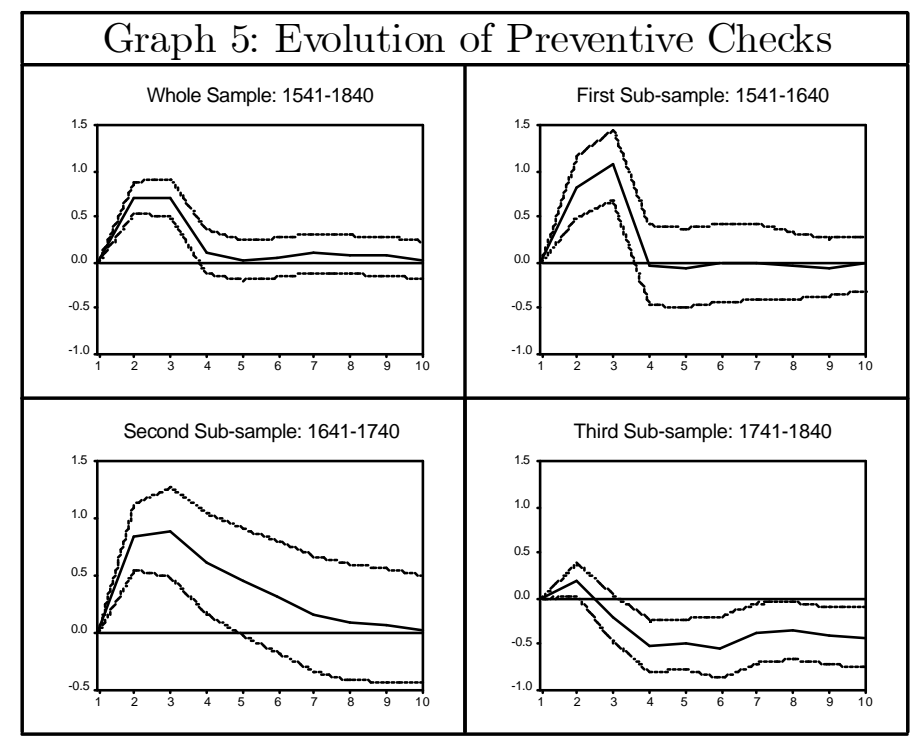

The accumulated responses of fertility are 1.87 for the whole sample and $1.69,3.41,-3.15$ for the three sub-samples respectively (Tables $2,3,4$, and $5) .{ }^{16}$ The percentage of CBR's variance explained by real wages is very important, considerably higher than in the case of mortality and it tends to increase with time (Tables $6,7,8$, and 9). These findings confirm that fertility was strongly influenced by real wages, more so than mortality, but that this influence did not always take the form that Malthus assumed: while the preventive check functioned as expected in the early Modern period, after 1740 the effect of higher wages is a decline in CBR instead of the increase which the Malthusian model relies on. The results of the last two sections imply that the two equilibrating mechanisms of the Malthusian model disappeared in Modern England before the middle of the 18th century.

\subsection{The response of real wages to changes in popula- tion}

In the Malthusian model wages are endogenous and negatively related with the level of population. Any increase in population translates into a decline in real wages because of diminishing marginal returns to labor. Hence, an

\footnotetext{
${ }^{16}$ This is the increase in number of births per thousand inhabitants due to an increase in real wages equivalent to one standard deviation. They correspond to changes of 5.52 $\%, 4.99 \%, 10.95 \%$ and $-8.56 \%$ respectively with respect to average fertility.
} 
exogenous increase in death rates or birth rates should produce an increase or a decrease in real wages respectively. The timing of the adjustment is obviously different: the impact of birth rates would affect real wages only after several years when the baby grows up and joins the labor force. The impact of mortality, as long as it is more or less homogenous across the agegroups, should be more rapid because it affects the labor force more directly. Given that the methodology of this paper focuses on short and medium-term responses, the lack of any significant impact of fertility on real wages should not be a surprise.

Impulse responses confirm that real wages are pushed up by an increase in mortality in the whole sample (IR 3-2 in Graph 6) and in the second sub-sample (IR 3-2, Graph 8). ${ }^{17}$ However, the increase is rather small and this mechanism is not significant in the first sub-sample and vanishes in the third sub-sample. The responses to a shock in fertility are, in general, not significant and the only significant effect, in the sub-sample beginning in 1740 , is a small -and puzzling- increase in real wages in the same year of the shock and a non-significant echo three years later (IR 3-1, Graph 9). Consequently, although the methodology pursued in this paper is not the best one to study the responses of wages to changes in population, it seems that real wages only reacted to changes in mortality as Malthus predicted in some periods.

\subsection{The debate about contraceptive efficiency}

The ability to intentionally modify the number of births to accommodate to changes in welfare should be linked to some voluntary method of contraception. Given that there is a consensus that the early modern English population was a "natural fertility" population, the literature has claimed that there was no significant fertility control within marriage. ${ }^{18}$ A population is considered to have a "natural fertility" regime if there is no noticeable reduction in fertility after a target number of children has been achieved. The strategy of suddenly reducing births within marriage is known as a "stopping" strategy. The detection of a clear pattern of stopping seems to provide strong evidence in favor of fertility control within marriage. However the

\footnotetext{
${ }^{17}$ Hereafter I will call the impulse response of file $i$ and column $j$ in each Graph IR $i-j$. For instance, IR 3-2 means that it is the third file and second column, and therefore corresponds to the response of real wages to mortality.

${ }^{18}$ For instance, Wrigley et al. (1997, p. 461).
} 
opposite is not true: the absence of evidence of stopping is not proof that fertility control within marriage did not exist (Wrigley 1997, p. 457-461). An alternative strategy to limit the number of children is based on "spacing" births which coincides with a more gradual reduction of the number of births and it is fully consistent with a natural fertility regime (Knodel 1987). Given that the English population has quite long birth intervals, the existence of an intentional fertility control based on a spacing strategy is a plausible hypothesis (Santow 1995) and in fact, there is some evidence that fertility control within marriage was not uncommon in some sectors of the English population in the seventeenth century (Wrigley 1966, Crafts and Ireland 1976).

Have the preventive checks operated through marriage during the "Malthusian" period? Did the sensitivity of fertility to wages rely only on the ability of prospective couples to forecast the economic future accurately and control the quantity of their offsprings by postponing or advancing marriage? The analysis of the dynamic response of marriage rates and birth rates to shocks in wages in a framework in which the exogenous component of each variable is properly identified can provide some indirect information about the incidence of contraception within marriage in pre-industrial England. Impulse response analysis show that both $\mathrm{CBR}$ and $\mathrm{CMR}$ increased after a positive shock in real wages. However, the reaction of birth rates is considerably greater than the reaction of marriage rates: in other words, assuming one new birth per new marriage, it is impossible to explain the increase in birth rates by the increase in marriage rates. The accumulated response of birth rates after a positive shock in wages amounts to $0.71,1.41$, and 1.53 in the first, second and third year after the shock, respectively while the equivalent responses of marriage rates are $0.46,0.58$ and 0.53 (Table 2). ${ }^{19}$ This implies that the positive shock in wages induced 0.71 per thousand new births one year later but only 0.46 per thousand new marriages and 1.41 new births two years later and only 0.53 new marriages. ${ }^{20}$ Consequently, changes in marital fertility account for half or more of the preventive check. Given that the share of the variability of birth rates explained by real wages is quite important, this finding suggests that a non-negligible number of couples were consciously able to avoid undesired pregnancy.

\footnotetext{
${ }^{19}$ Comparability of the responses is straightforward because both variables (CBR and $\mathrm{CMR}$ ) are rates measured in relation to the same population.

${ }^{20}$ This pattern is quite stable across the three subsamples. See IR's 1-3 and 4-3 in Graphs 6, 7, 8 and 9 .
} 


\subsection{Other Interactions}

The estimation also provides meaningful information about other interactions which for reasons of space I simply mention here. For instance, marriage rates respond positively not only to shocks in real wages (IR 4-3, Graph 6) but also to shocks in mortality (IR 4-2, Graph 6). This is consistent with a certain number of re-marriages of widows and widowers (Lee 1981) and also with the hypothesis that higher mortality increased access to land for prospective couples (Ohlin 1961, Goldstone 1986). Marriage rates also increased after an exogenous shock in fertility (IR 4-1) suggesting that pre-nuptially conceived births could be the ultimate "cause" of a certain number of marriages. The fact that this response is stronger in the first and third sub-samples (Graphs 7 and 9) than in the second (Graph 8) coincides with the evolution of the importance of pre-nuptial conception in pre-industrial England (Wrigley et al. 1997). The response of CBR after an increase in marriage rates has the expected positive sign in the first two sub-samples (IR 1-4, Graphs 7 and 8) but it is negative (although barely significant) in the third sub-sample (IR 1-4, Graph 9). Finally, the interaction between fertility and mortality will be considered in further detail in the next section.

\subsubsection{The relation between fertility and mortality}

The response of CBR after a shock in CDR is as expected: initially it is negative because an upsurge of mortality is associated with worse health conditions which reduces the probability of pregnancy. Afterwards it shows a positive echo, consistent with a shortening of breast-feeding and with the hypothesis that new babies are intentionally conceived to replace those who died (Lee 1981, Galloway 1988).

The interpretation of the response of mortality after a shock in fertility is less straightforward. Since mortality is usually higher among newly-born babies, the death rate is expected to rise after an increase in CBR. However, the results of the estimation show almost exactly the opposite: in the whole sample and the three sub-samples there is a reduction of mortality (IR 2-1 of Graphs 6 to 9) although in some cases this is barely significant. This result is quite similar to what Eckstein et al. (1986) found when they estimated a VAR system for pre-industrial Sweden including Infant Death Rates as an endogenous variable: there is no significant response of infant mortality to shocks in fertility after years after the shock. It is not possible to compare 
this result with previous estimations using distributed lags models because, in almost all cases, mortality is assumed to depend only on prices and fertility is excluded from the regression. ${ }^{21}$

A strong correlation between shocks in mortality and foetal loss could eventually explain this pattern and, at the same time, it could undermine the plausibility of one of my identification assumptions. If positive shocks in mortality generate a jump in foetal loss, they should also produce an endogenous decline of CBR in the same year of the shock. Given that my identification assumption precludes any endogenous response of CBR, that correlation can eventually produce the observed negative response of mortality after a positive shock in fertility. A possible way to test the implications of this hypothesis on my identification strategy is to estimate the system with a permutation of the ordering of the vector $\mathrm{Y}$ locating CDR before CBR. In this way, the restriction that fertility can not react -within a year- to a shock in mortality is replaced by the assumption that mortality can not react to a shock in fertility. The results of this experiment are presented in Graph 10 and it is quite easy to check that the negative response of mortality after a shock in fertility is still present and, more importantly, the other IRs are very similar to those obtained with the original specification.

\section{Conclusions}

The endogenous nature of all the relevant variables during the so-called Malthusian period makes the estimation of their interactions particularly difficult. This paper explores the advantages of using the VAR methodology with short-run restrictions to estimate those interactions. The results of the estimation suggest that the English demographic system started to move away from Malthusian dynamics well before the Industrial Revolution. One of the key equilibrating mechanisms of the Malthusian model, the positive check, was relevant only until the middle of the 17th century. The other mechanism, the preventive check, changed dramatically in the second half of the 18th century when higher wages started to induce a decline in birth rates. An increase in real wages was no longer inducing an increase in population any more. This finding is consistent with the fact that between 1750

\footnotetext{
${ }^{21}$ For England, see Lee (1981), for Sweden, see Richards (1984), for Europe in general, see Galloway (1988). Lee and Anderson (2002) assume that mortality depends only on real wages and exogenous factors like weather and disease prevalence.
} 
and 1810 population levels increased at extraordinarily high rates while real wages were not higher than the average pre-industrial level.

The other finding of this paper suggests that demographic patterns in England during the early modern period were clearly more modern than previously thought. The simultaneous estimation of the relationship between birth rates, marriage rates and wages provides evidence that marriage strategies were not the only way to control fertility: preventive checks also operated through the use of some conscious contraceptive mechanism within marriage.

These results are consistent with a growing evidence that the English economy did not experience a rapid change concentrated in few decades at the end of the 18th and the beginning of the 19th century but rather that transformation was more gradual and slow. From a demographic point of view, the results of this paper reveal that the escape from an economy rigidly governed by the laws of the Malthusian model has been probably much earlier than the onset of the modern economic growth related with the Industrial Revolution of the 19th century. Perhaps, the world before Malthus was not so Malthusian.

\section{References}

[1] Allen, Robert (2001): "The Great Divergence in European Wages and Prices from the Middle Ages to the First World War", Explorations in Economic History, 38, 411-447.

[2] Bailey, R.E. and Chambers, M.J. (1993): "Long-Term Demographic Interactions in Precensus England", Journal of the Royal Statistics Society, 156, 3, 339-362.

[3] Bengtsson, Tommy and Göran Broström (1997): "Distinguishing TimeSeries Models by Impulse Response. A Case Study of Mortality and Population Economy", Historical Methods, 30,4, 165-171.

[4] Boongarts, John (1978): "A framework for analyzing the proximate determinants of fertility", Population and Development Review, 4, 2, 105132.

[5] Canova, Fabio (1995a): "The Economics of VAR Models" in Hoover, Kevin D.: Macroeconometrics. Developments, Tensions and Prospects, Kluwer Academics, Boston, 57-97. 
[6] Canova, Fabio (1995b): "Vector Autoregression Models: Specification, Estimation, Inference, and Forecasting" in Pesaran, M.H., and Wickens, Michael, R. (eds.): Handbook of applied econometrics, Vol. 1, 73-138.

[7] Chatfield, Christopher (1996): The analysis of Time Series: an introduction, Chapman and Hall, London.

[8] Christiano, Lawrence J.; Eichenbaum, Martin; Evans, Charles L. (1998): "Monetary policy shocks: what have we learned and to what end?", NBER Working Paper \# 6400.

[9] Crafts, N.F.R. and Ireland, N.J. (1976): "Family limitation and the English demographic revolution: a simulation approach", Journal of Economic History, 36, 598-623.

[10] Eckstein, Zvi, Paul Schultz and Kenneth I. Wolpin (1986): "Short Run Fluctuations in Fertility and Mortality in Pre-Industrial Sweden", European Economic Review, 26, 295-317.

[11] Galor, Oded (2004): "From Stagnation to Growth: Unified Growth Theory", CEPR Working Paper \# 4581.

[12] Galor, Oded and Weil, David N. (2000): "Population, Technology and Growth: from the Malthusian Regime to the Demographic Transition and Beyond", American Economic Review, 90, 4, 806-828.

[13] Galloway, Patrick R. (1988): "Basic Patterns in Annual Variations in Fertility, Nuptiality, Mortality and Prices in Pre-industrial Europe", Population Studies, 42, 275-303.

[14] Goldstone, Jack (1986) : "The Demographic Revolution in England: A Re-examination", Population Studies, 49, 5-33.

[15] Grantham, George (1999): "Contra Ricardo: On the Macroeconomics of Pre-industrial Economies", European Review of Economic History, 3, 2, 199-232.

[16] Hagnell, Mats (1991): "A Multivariate Time Series Analysis of Fertility, Adult Mortality, Nuptiality, and Real Wages in Sweden 1751-1850: A Comparison of Two Different Approaches", Journal of Official Statistics, $7,4,437-455$. 
[17] Hansen, Gary and Prescott, Edward (1998): "Malthus to Solow", NBER Working Paper \# 6858.

[18] Kögel, Tomas and Prskawetz, Alexia (2001): "Agricultural Productivity Growth and Escape from the Malthusian Trap", Journal of Economic Growth, 6, 337-357, 2001.

[19] Knodel, J. (1987): "Starting, stopping and spacing during early stages of the Fertility Transition: The experience of German Village Populations in the 18th and 19th centuries", Demography, 24, 143-162.

[20] Kremer, Michael (1993): "Population Growth and Technological Change: One Million B.C. To 1990", Quarterly Journal of Economics, 108, 3, 681-716.

[21] Lagerlof, Nils-Peter (2003): "From Malthus to Modern Growth: Can Epidemics Explain the Three Regimes?", International Economic Review, $44,2,755-777$.

[22] Lee, Ronald Demos (1981): "Short Term Variation: vital rates, prices and weather" in Wrigley and Schofield: The Population History of England, 1541-1871. A reconstruction, Arnold, 357-401.

[23] Lee, Ronald Demos (1985a): "Inverse Projection and Back Projection: a Critical Appraisal, and Comparative Results for England, 1539 to 1871", Population Studies, 39, 233-248.

[24] Lee, Ronald Demos (1985b): "Population Homeostasis and English Demographic History", Journal of Interdisciplinary History, 15, 4, 635-660.

[25] Lee, Ronald Demos (1993): "Inverse Projection and Demographic Fluctuations. A Critical Assessment of New Methods" in Reher, David and Roger Schofield: Old and new Methods in Historical Demography, Oxford, Clarendon Press, 7-28.

[26] Lee, Ronald (1997): "Population Dynamics: Equilibrium, Disequilibrium, and Consequences of Fluctuations", in Rosenzweig, M. and Oded Stark (eds.): Handbook of Population and Family Economics, Volume 1B, 1063-1115. 
[27] Lee, Ronald and Anderson, Michael (2002): "Malthus in State Space: Macro economic-demographic relations in English history, 1540 to 1870", Journal of Population Economics, 15, 195-220.

[28] Lucas, Robert (2002): Lectures on Economic Growth, Harvard University Press.

[29] Mills, J.W. (1994): New Evidence on the Demographic Transition in England, Ph.D. Dissertation in Economics at the State University of New York at Stony Brook.

[30] Nicolini, Esteban A. (2004): "Mortality, interest rates, investment, and agricultural production in 18th century England", Explorations in Economic History, 41, 130-155.

[31] Ohlin, G. (1961): "Mortality, Marriage, and Growth in Pre-Industrial Populations", Population Studies, 14, 190-197.

[32] Palloni, Alberto, Kenneth Hill and Guido Pinto Aguirre (1996): "Economic Swings and Demographic Changes in the History of Latin America", Population Studies, 50, 105-132.

[33] Phelps Brown, E.H. and Hopkins, Sheila V. (1956): "Seven Centuries of the Prices of Consumables Compared with Builder's wage rates", Economica, 23, 296-314.

[34] Santow, Gigi (1995): "Coitus Interruptus and the Control of Natural Fertility", Population Studies, 49, 19-43.

[35] Tsoulouhas, Theofanis (1992): "A New Look at Demographic and Technological Changes: England 1550-1839", Explorations in Economic History, 29, 2, 169-203.

[36] Weir, David (1984): "Life Under Pressure: France and England, 16701870", Journal of Economic History, 44, 1, 27-47.

[37] Wrigley, E.A. (1966): "Family limitation in pre-industrial England", Economic History Review, 19, 1, 82-109.

[38] Wrigley, E.A.; Davies, R.S; Oeppen, J.E.; and Schofield, R.S. (1997): English population history from family reconstitution 1580-1837, Cambridge University Press, Cambridge. 
[39] Wrigley, E.A. and Schofield, R.S. (1981): The Population History of England1541-1871. A reconstruction, Edward Arnold, London.

\section{Graphs and tables}

\subsection{Graphs with Impulses Responses}

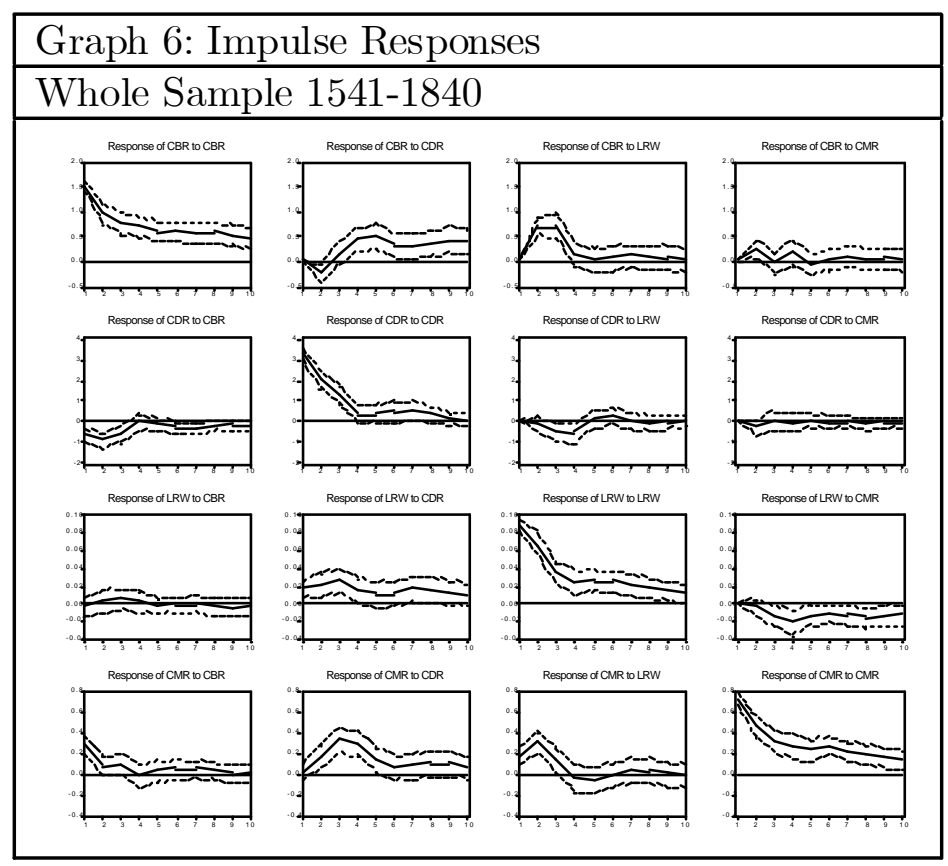




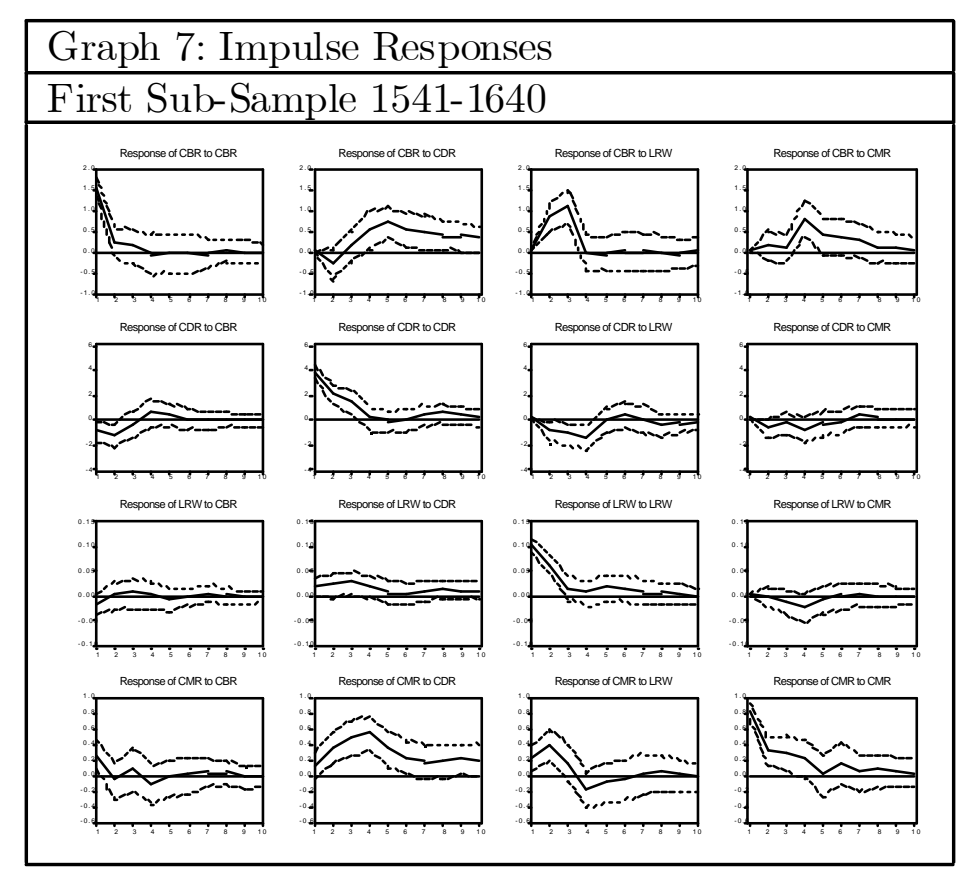

Graph 8: Impulse Responses

Second Sub-Sample 1641-1740

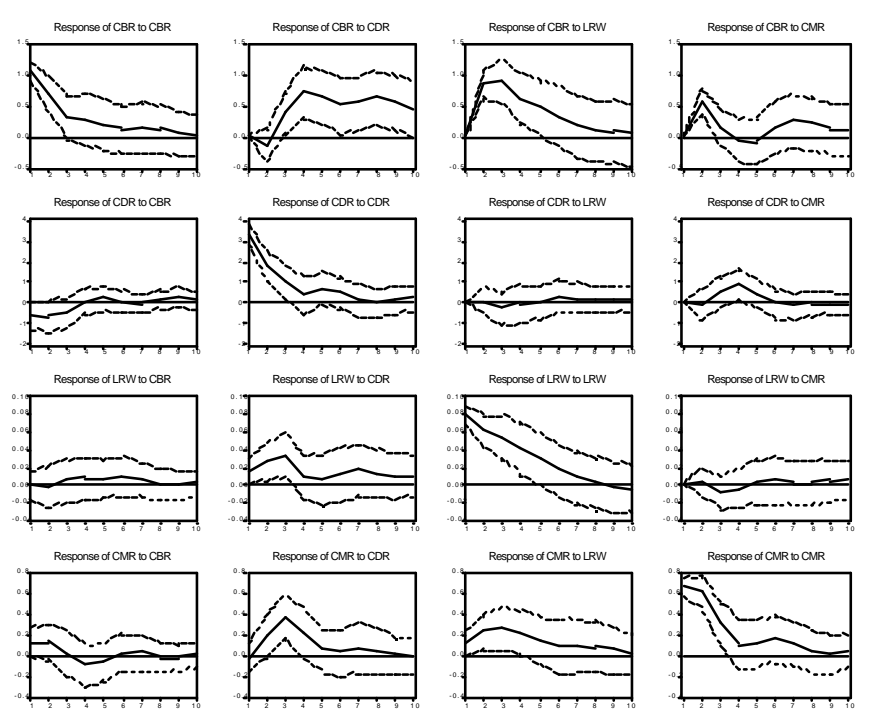



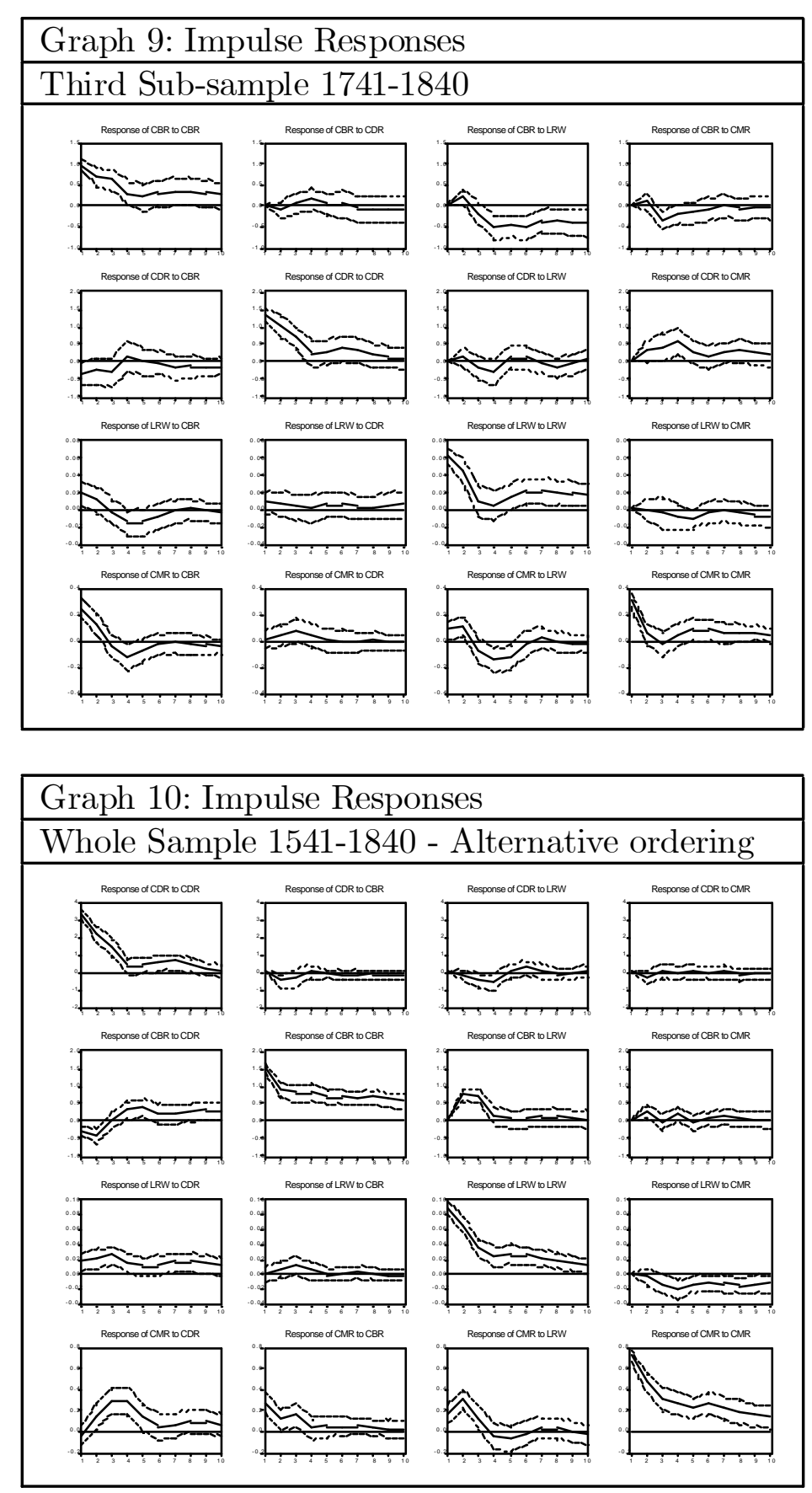


\subsection{Tables}

Table 2

\begin{tabular}{|l|l|l|l|l|}
\hline \multicolumn{5}{|l|}{ Accumulated Impulse Responses } \\
\hline \multicolumn{5}{|l|}{ Whole Sample:1541-1840 } \\
\hline Responses of CBR \\
\hline Year & CBR & CDR & LRW & CMR \\
\hline 1 & 1.506 & 0.000 & 0.000 & 0.000 \\
\hline 2 & 2.443 & -0.267 & 0.707 & 0.238 \\
\hline 3 & 3.202 & -0.126 & 1.410 & 0.185 \\
\hline 4 & 3.895 & 0.311 & 1.526 & 0.347 \\
\hline 5 & 4.488 & 0.801 & 1.548 & 0.269 \\
\hline 10 & 7.230 & 2.589 & 1.869 & 0.539 \\
\hline Responses of CDR \\
\hline 1 & -0.689 & 3.196 & 0.000 & 0.000 \\
\hline 2 & -1.667 & 5.147 & -0.226 & -0.338 \\
\hline 3 & -2.316 & 6.399 & -0.744 & -0.312 \\
\hline 4 & -2.415 & 6.697 & -1.339 & -0.368 \\
\hline 5 & -2.589 & 7.035 & -1.303 & -0.351 \\
\hline 10 & -3.830 & 8.438 & -1.256 & -0.779 \\
\hline Responses of LRW \\
\hline 1 & -0.005 & 0.015 & 0.087 & 0.000 \\
\hline 2 & -0.003 & 0.036 & 0.152 & -0.005 \\
\hline 3 & 0.001 & 0.061 & 0.185 & -0.020 \\
\hline 4 & 0.002 & 0.075 & 0.207 & -0.043 \\
\hline 5 & -0.001 & 0.085 & 0.233 & -0.057 \\
\hline 10 & -0.014 & 0.146 & 0.321 & -0.126 \\
\hline Responses of CMR & \\
\hline 1 & 0.272 & 0.006 & 0.160 & 0.714 \\
\hline 2 & 0.349 & 0.167 & 0.460 & 1.174 \\
\hline 3 & 0.431 & 0.484 & 0.582 & 1.479 \\
\hline 4 & 0.399 & 0.774 & 0.534 & 1.745 \\
\hline 5 & 0.414 & 0.906 & 0.466 & 1.965 \\
\hline 10 & 0.527 & 0.280 & 0.464 & 2.919 \\
\hline \multicolumn{5}{|l}{} \\
\hline 5
\end{tabular}

Table3

\begin{tabular}{|l|l|l|l|l|}
\hline \multicolumn{5}{|l|}{ Accumulated Impulse Responses } \\
\hline \multicolumn{5}{|l|}{ First Sub-sample:1541-1640 } \\
\hline Responses of CBR \\
\hline Year & CBR & CDR & LRW & CMR \\
\hline 1 & 1.536 & 0.000 & 0.000 & 0.000 \\
\hline 2 & 1.720 & -0.326 & 0.826 & 0.120 \\
\hline 3 & 1.825 & -0.206 & 1.887 & 1.157 \\
\hline 4 & 1.735 & 0.298 & 1.855 & 0.936 \\
\hline 5 & 1.684 & 0.964 & 1.794 & 1.286 \\
\hline 10 & 1.579 & 0.948 & 1.686 & 2.080 \\
\hline Responses of CDR \\
\hline 1 & -0.948 & 3.735 & 0.000 & 0.000 \\
\hline 2 & -2.240 & 5.727 & -0.949 & -0.667 \\
\hline 3 & -2.674 & 7.013 & -2.186 & -1.074 \\
\hline 4 & -2.207 & 7.015 & -3.720 & -1.934 \\
\hline 5 & -1.889 & 6.822 & -3.847 & -2.293 \\
\hline 10 & -2.107 & 7.849 & -4.604 & -1.981 \\
\hline Responses of LRW \\
\hline 1 & -0.017 & 0.018 & 0.098 & 0.000 \\
\hline 2 & -0.019 & 0.038 & 0.159 & -0.005 \\
\hline 3 & -0.015 & 0.063 & 0.173 & -0.018 \\
\hline 4 & -0.015 & 0.080 & 0.176 & -0.046 \\
\hline 5 & -0.023 & 0.085 & 0.191 & -0.055 \\
\hline 10 & -0.030 & 0.133 & 0.217 & -0.055 \\
\hline Responses of CMR \\
\hline 1 & 0.252 & 0.104 & 0.215 & 0.815 \\
\hline 2 & 0.171 & 0.449 & 0.598 & 1.129 \\
\hline 3 & 0.233 & 0.927 & 0.744 & 1.396 \\
\hline 4 & 0.098 & 1.455 & 0.546 & 1.609 \\
\hline 5 & 0.053 & 1.780 & 0.450 & 1.593 \\
\hline 10 & 0.060 & 2.714 & 0.363 & 1.875 \\
\hline \multicolumn{5}{|l}{} \\
\hline 5
\end{tabular}


Table 4

\begin{tabular}{|c|c|c|c|c|}
\hline \multicolumn{5}{|c|}{ Accumulated Impulse Responses } \\
\hline \multicolumn{5}{|c|}{ Second Sub-sample 1641-1740 } \\
\hline \multicolumn{5}{|c|}{ CBR } \\
\hline Year & $\mathrm{CBR}$ & CDR & LRW & CMR \\
\hline 1 & 1.031 & 0.000 & 0.000 & 0.000 \\
\hline 2 & 1.684 & -0.153 & 0.834 & 0.556 \\
\hline 3 & 1.993 & 0.204 & 1.709 & 0.699 \\
\hline 4 & 2.260 & 0.904 & 2.314 & 0.629 \\
\hline 5 & 2.436 & 1.524 & 2.756 & 0.546 \\
\hline 10 & 2.860 & 4.101 & 3.408 & 1.333 \\
\hline \multicolumn{5}{|l|}{ CDR } \\
\hline 1 & -0.613 & 3.230 & 0.000 & 0.000 \\
\hline 2 & -1.310 & 4.497 & 0.010 & -0.111 \\
\hline 3 & -1.810 & 5.854 & -0.312 & 0.290 \\
\hline 4 & -1.789 & 6.160 & -0.396 & 1.096 \\
\hline 5 & -1.602 & 6.798 & -0.405 & 1.465 \\
\hline 10 & -1.211 & 7.585 & 0.547 & 0.959 \\
\hline \multicolumn{5}{|l|}{ LRW } \\
\hline 1 & -0.002 & 0.014 & 0.077 & 0.000 \\
\hline 2 & -0.005 & 0.039 & 0.137 & 0.002 \\
\hline 3 & -0.001 & 0.072 & 0.189 & -0.007 \\
\hline 4 & 0.006 & 0.080 & 0.229 & -0.012 \\
\hline 5 & 0.013 & 0.086 & 0.057 & -0.009 \\
\hline 10 & 0.028 & 0.144 & 0.273 & 0.007 \\
\hline \multicolumn{5}{|c|}{ CMR } \\
\hline 1 & 0.021 & -0.042 & 0.104 & 0.648 \\
\hline 2 & 0.242 & 0.134 & 0.321 & 1.250 \\
\hline 3 & 0.241 & 0.500 & 0.573 & 1.550 \\
\hline 4 & 0.135 & 0.694 & 0.788 & 1.650 \\
\hline 5 & 0.063 & 0.735 & 0.912 & 1.757 \\
\hline 10 & 0.038 & 0.825 & 1.208 & 2.071 \\
\hline
\end{tabular}

Table 5

\begin{tabular}{|c|c|c|c|c|}
\hline \multicolumn{5}{|c|}{ Accumulated Impulse Responses } \\
\hline \multicolumn{5}{|c|}{ Third Sub-sample 1741-1840 } \\
\hline \multicolumn{5}{|c|}{$\mathrm{CBR}$} \\
\hline Year & $\mathrm{CBR}$ & CDR & LRW & CMR \\
\hline 1 & 0.943 & 0.000 & 0.000 & 0.000 \\
\hline 2 & 1.625 & -0.121 & 0.194 & 0.070 \\
\hline 3 & 2.224 & -0.061 & -0.023 & -0.297 \\
\hline 4 & 2.298 & 0.072 & -0.544 & -0.511 \\
\hline 5 & 2.690 & 0.095 & -1.044 & -0.692 \\
\hline 10 & 4.164 & -0.182 & -3.152 & -0.984 \\
\hline \multicolumn{5}{|c|}{ CDR } \\
\hline 1 & -0.371 & 1.000 & 0.000 & 0.000 \\
\hline 2 & -0.645 & 2.295 & 0.086 & 0.265 \\
\hline 3 & -0.971 & 2.936 & -0.145 & 0.648 \\
\hline 4 & -0.862 & 3.145 & -0.472 & 1.190 \\
\hline 5 & -0.885 & 3.402 & -0.374 & 1.413 \\
\hline 10 & -1.615 & 4.433 & -0.609 & 2.439 \\
\hline \multicolumn{5}{|c|}{ LRW } \\
\hline 1 & 0.018 & 0.008 & 0.060 & 0.000 \\
\hline 2 & 0.029 & 0.015 & 0.104 & -0.001 \\
\hline 3 & 0.026 & 0.017 & 0.112 & -0.006 \\
\hline 4 & 0.010 & 0.018 & 0.117 & -0.015 \\
\hline 5 & -0.004 & 0.024 & 0.131 & -0.026 \\
\hline 10 & -0.021 & 0.045 & 0.227 & -0.050 \\
\hline \multicolumn{5}{|c|}{ CMR } \\
\hline 1 & 0.243 & 0.006 & 0.080 & 0.309 \\
\hline 2 & 0.366 & 0.045 & 0.192 & 0.355 \\
\hline 3 & 0.318 & 0.119 & 0.106 & 0.326 \\
\hline 4 & 0.185 & 0.153 & -0.050 & 0.364 \\
\hline 5 & 0.108 & 0.153 & -0.178 & 0.450 \\
\hline 10 & -0.057 & 0.111 & -0.245 & 0.750 \\
\hline
\end{tabular}


Table 6

\begin{tabular}{|c|c|c|c|c|}
\hline \multicolumn{5}{|c|}{ Variance Decomposition } \\
\hline \multicolumn{5}{|c|}{ Whole Sample 1541-1840 } \\
\hline \multicolumn{5}{|c|}{ CBR } \\
\hline Year & $\mathrm{CBR}$ & CDR & LRW & CMR \\
\hline 1 & 100.00 & 0.000 & 0.000 & 0.000 \\
\hline 2 & 83.367 & 1.888 & 13.241 & 1.504 \\
\hline 3 & 76.489 & 1.873 & 20.412 & 1.226 \\
\hline 4 & 75.344 & 5.060 & 18.053 & 1.543 \\
\hline 5 & 73.744 & 8.450 & 16.314 & 1.492 \\
\hline 10 & 72.429 & 13.963 & 12.306 & 1.301 \\
\hline \multicolumn{5}{|l|}{ CDR } \\
\hline 1 & 4.444 & 95.556 & 0.000 & 0.000 \\
\hline 2 & 9.163 & 89.781 & 0.326 & 0.730 \\
\hline 3 & 10.362 & 87.210 & 1.786 & 0.641 \\
\hline 4 & 10.157 & 85.526 & 3.674 & 0.642 \\
\hline 5 & 10.241 & 85.468 & 3.651 & 0.639 \\
\hline 10 & 11.387 & 83.963 & 3.825 & 0.824 \\
\hline \multicolumn{5}{|l|}{ LRW } \\
\hline 1 & 0.278 & 3.012 & 96.709 & 0.000 \\
\hline 2 & 0.191 & 5.185 & 94.395 & 0.228 \\
\hline 3 & 0.317 & 8.915 & 89.029 & 1.738 \\
\hline 4 & 0.299 & 9.521 & 85.413 & 4.767 \\
\hline 5 & 0.333 & 9.495 & 84.448 & 5.725 \\
\hline 10 & 0.477 & 11.775 & 78.147 & 9.600 \\
\hline \multicolumn{5}{|c|}{ CMR } \\
\hline 1 & 12.156 & 0.006 & 4.178 & 83.661 \\
\hline 2 & 8.489 & 2.776 & 12.265 & 76.470 \\
\hline 3 & 7.487 & 10.926 & 11.275 & 70.312 \\
\hline 4 & 6.666 & 16.001 & 10.102 & 67.230 \\
\hline 5 & 6.343 & 16.437 & 9.917 & 67.302 \\
\hline 10 & 5.683 & 15.929 & 8.704 & 69.684 \\
\hline
\end{tabular}

Table 7

\begin{tabular}{|c|c|c|c|c|}
\hline \multicolumn{5}{|c|}{ Variance Decomposition } \\
\hline \multicolumn{5}{|c|}{ First Sub-sample 1541-1640 } \\
\hline \multicolumn{5}{|c|}{ CBR } \\
\hline Year & CBR & $\mathrm{CDR}$ & $\mathrm{LRW}$ & CMR \\
\hline 1 & 100.000 & 0.000 & 0.000 & 0.000 \\
\hline 2 & 74.863 & 3.327 & 21.357 & 0.453 \\
\hline 3 & 55.287 & 2.779 & 41.569 & 0.364 \\
\hline 4 & 46.223 & 7.173 & 34.664 & 11.933 \\
\hline 5 & 41.709 & 14.117 & 31.304 & 12.870 \\
\hline 10 & 35.551 & 24.023 & 26.679 & 13.747 \\
\hline \multicolumn{5}{|c|}{$\mathrm{CDR}$} \\
\hline 1 & 6.057 & 93.943 & 0.000 & 0.000 \\
\hline 2 & 11.764 & 82.078 & 4.121 & 2.035 \\
\hline 3 & 10.865 & 77.147 & 9.584 & 2.404 \\
\hline 4 & 10.373 & 68.241 & 16.679 & 4.707 \\
\hline 5 & 10.620 & 67.701 & 16.571 & 5.107 \\
\hline 10 & 10.304 & 66.611 & 17.692 & 5.392 \\
\hline \multicolumn{5}{|c|}{ LRW } \\
\hline 1 & 3.065 & 3.217 & 93.718 & 0.000 \\
\hline 2 & 2.203 & 4.972 & 92.659 & 0.166 \\
\hline 3 & 2.150 & 8.741 & 87.791 & 1.317 \\
\hline 4 & 2.014 & 9.902 & 82.272 & 5.813 \\
\hline 5 & 2.359 & 9.849 & 81.579 & 6.213 \\
\hline 10 & 2.504 & 12.194 & 79.300 & 6.002 \\
\hline \multicolumn{5}{|c|}{ CMR } \\
\hline 1 & 8.073 & 1.370 & 5.874 & 84.683 \\
\hline 2 & 6.048 & 11.247 & 16.671 & 66.035 \\
\hline 3 & 4.985 & 24.197 & 14.469 & 56.349 \\
\hline 4 & 4.951 & 34.197 & 13.625 & 47.227 \\
\hline 5 & 4.757 & 37.520 & 13.281 & 44.441 \\
\hline 10 & 4.415 & 41.982 & 12.388 & 41.215 \\
\hline
\end{tabular}


Table 8

\begin{tabular}{|c|c|c|c|c|}
\hline \multicolumn{5}{|c|}{ Variance Decomposition } \\
\hline \multicolumn{5}{|c|}{ Second Sub-sample 1641-1740 } \\
\hline \multicolumn{5}{|c|}{ CBR } \\
\hline Year & CBR & CDR & LRW & CMR \\
\hline 1 & 100.000 & 0.000 & 0.000 & 0.000 \\
\hline 2 & 59.168 & 0.927 & 27.615 & 12.290 \\
\hline 3 & 44.939 & 4.270 & 41.440 & 9.350 \\
\hline 4 & 37.141 & 14.379 & 40.977 & 7.504 \\
\hline 5 & 33.231 & 20.201 & 39.843 & 6.725 \\
\hline 10 & 25.718 & 35.215 & 31.983 & 7.084 \\
\hline \multicolumn{5}{|l|}{ CDR } \\
\hline 1 & 3.470 & 96.530 & 0.000 & 0.000 \\
\hline 2 & 6.040 & 93.872 & 0.001 & 0.086 \\
\hline 3 & 7.130 & 91.094 & 0.666 & 1.110 \\
\hline 4 & 6.806 & 87.487 & 0.679 & 5.029 \\
\hline 5 & 6.779 & 86.899 & 0.656 & 5.665 \\
\hline 10 & 6.964 & 85.403 & 1.722 & 5.910 \\
\hline \multicolumn{5}{|l|}{ LRW } \\
\hline 1 & 0.057 & 3.195 & 96.748 & 0.000 \\
\hline 2 & 0.108 & 8.033 & 91.831 & 0.029 \\
\hline 3 & 0.184 & 13.278 & 86.004 & 0.534 \\
\hline 4 & 0.476 & 12.226 & 86.641 & 0.657 \\
\hline 5 & 0.716 & 11.826 & 86.875 & 0.672 \\
\hline 10 & 1.270 & 14.958 & 82.726 & 1.043 \\
\hline \multicolumn{5}{|c|}{ CMR } \\
\hline 1 & 3.276 & 0.394 & 2.406 & 93.924 \\
\hline 2 & 3.243 & 3.636 & 6.429 & 86.692 \\
\hline 3 & 2.458 & 14.028 & 10.215 & 73.299 \\
\hline 4 & 3.130 & 15.794 & 12.938 & 68.138 \\
\hline 5 & 3.441 & 15.516 & 13.774 & 67.269 \\
\hline 10 & 3.414 & 15.283 & 14.696 & 66.607 \\
\hline
\end{tabular}

Table 9

\begin{tabular}{|c|c|c|c|c|}
\hline \multicolumn{5}{|c|}{ Variance Decomposition } \\
\hline \multicolumn{5}{|c|}{ Third Sub-sample 1741-1840 } \\
\hline \multicolumn{5}{|c|}{ CBR } \\
\hline Year & $\mathrm{CBR}$ & CDR & LRW & $\mathrm{CMR}$ \\
\hline 1 & 100.000 & 0.000 & 0.000 & 0.000 \\
\hline 2 & 95.957 & 1.037 & 2.657 & 0.349 \\
\hline 3 & 87.606 & 0.931 & 4.317 & 7.146 \\
\hline 4 & 75.580 & 1.521 & 15.059 & 7.839 \\
\hline 5 & 67.951 & 1.360 & 22.568 & 8.122 \\
\hline 10 & 55.557 & 1.463 & 37.127 & 5.854 \\
\hline \multicolumn{5}{|c|}{$\mathrm{CDR}$} \\
\hline 1 & 7.471 & 92.529 & 0.000 & 0.000 \\
\hline 2 & 7.155 & 90.229 & 0.250 & 2.367 \\
\hline 3 & 8.643 & 83.839 & 1.652 & 5.867 \\
\hline 4 & 7.977 & 75.665 & 4.047 & 12.310 \\
\hline 5 & 7.754 & 74.979 & 4.155 & 13.112 \\
\hline 10 & 9.087 & 70.163 & 4.825 & 15.924 \\
\hline \multicolumn{5}{|c|}{ LRW } \\
\hline 1 & 7.989 & 1.452 & 90.559 & 0.000 \\
\hline 2 & 7.223 & 1.756 & 90.988 & 0.032 \\
\hline 3 & 7.237 & 1.831 & 90.513 & 0.420 \\
\hline 4 & 10.468 & 1.746 & 86.230 & 1.556 \\
\hline 5 & 12.696 & 2.123 & 81.927 & 3.254 \\
\hline 10 & 10.704 & 2.739 & 82.572 & 3.986 \\
\hline \multicolumn{5}{|c|}{ CMR } \\
\hline 1 & 36.665 & 0.021 & 3.997 & 59.317 \\
\hline 2 & 38.611 & 0.801 & 9.830 & 50.758 \\
\hline 3 & 36.756 & 3.394 & 12.606 & 47.243 \\
\hline 4 & 37.209 & 3.268 & 19.997 & 39.525 \\
\hline 5 & 35.421 & 2.925 & 23.674 & 37.981 \\
\hline 10 & 34.203 & 2.788 & 22.403 & 40.606 \\
\hline
\end{tabular}

